\title{
A Preliminary Survey of Interprofessional Education
}

\author{
Mary E. Rafter, B.Dent.Sc., M.S.; Igor J. Pesun, D.M.D., M.S.; Michael Herren, D.M.D.; \\ Jeffrey C. Linfante, D.M.D.; Mina Mina, D.M.D., M.S.D., Ph.D.; Christine D. Wu, M.S., \\ Ph.D.; Jane P. Casada, D.M.D.
}

\begin{abstract}
The purpose of this article is to review the literature on interprofessional education (IPE) and report on a preliminary survey of the current status of interprofessional education in seven academic health centers (AHCs) that have schools of dentistry associated with them. There is wide variability in interpretation of the term "interprofessional," and many barriers to interprofessional education exist including already overcrowded curricula in health professions schools, lack of support from faculty and administration, and financial constraints. Based on interviews completed at the authors' home institutions, it was recommended that topics such as ethics, communication skills, evidence-based practice, and informatics could be effectively taught in an interprofessional manner. Currently, some academic health centers are attempting to develop interprofessional education programs, but most of these efforts do not include dental students. Of the seven AHCs investigated in this study, only two had formal interprofessional educational activities that involved students from two or more health professions education programs. Dental school participants in this study professed a strong interest in interprofessional programs, but many interviewees from other professional schools and AHC administrators perceived that the dental school was isolated from other schools and disinterested in IPE. Many health care setting models in the future will include dentists as part of an interdisciplinary health care team; consequently, it is important for dental schools to become an active participant in future interprofessional educational initiatives.
\end{abstract}

\begin{abstract}
Dr. Rafter is Associate Professor and Director of Predoctoral Endodontics, Department of Cariology, Restorative Sciences, and Endodontics, University of Michigan; Dr. Pesun is Associate Professor, Division of Prosthodontics, Department of Restorative Sciences, University of Minnesota; Dr. Herren is Assistant Professor, OHP/Restorative Dentistry and Clinical Team Leader, University of Kentucky School of Dentistry; Dr. Linfante is Assistant Professor, Department of Restorative Dentistry and Director of Predoctoral Admissions and Student Recruitment, University of Medicine and Dentistry of New Jersey; Dr. Mina is Professor and Chair, Division of Pediatric Dentistry, Department of Oral and Maxillofacial Surgery, Orthodontics, Pediatric Dentistry, and Advanced General Dentistry, University of Connecticut; Dr. Wu is Associate Dean for Research and Professor of Periodontics, University of Illinois at Chicago; and Dr. Casada is Professor and Interim Chair, Department of Diagnostic Sciences, Prosthodontics, and Restorative Dentistry, University of Louisville. Direct correspondence and requests for reprints to Dr. Igor Pesun, University of Minnesota, 9-450B Moos Tower, 515 Delaware Street, SE, Minneapolis, MN 55455; 612-625-3924 phone; 612-625-1496 fax; Pesun001@umn.edu.
\end{abstract}

Key words: dental education, interprofessional education, predoctoral curriculum

Submitted for publication 5/9/05; accepted 12/8/05

$\mathrm{O}$ ral health is an integral and essential component of general health and well-being. The future dental graduate will have to function as part of a multidisciplinary health care team, treat more medically compromised patients, and apply scientific evidence to the treatment and prevention of oral and systemic disease. Dental education emerged in the mid-1800s as a distinct and autonomous educational system. It was considered that oral health care primarily involved mechanical treatment of the hard tissues. Consequently, dental education now faces a number of challenges in its efforts to train dental graduates who will interact and be understood by other health care professionals. At a recent conference evaluating dental education (Santa Fe Group), participants determined that an important factor responsible for the difficulties in dental education was the "silo" approach so commonly found in health education: "By their reliance on independent curricula, faculty, facilities, and research programs, 'silos' contribute to the isolation of health professional training programs." Speakers hypothesized that "a more effective outcome could be achieved if dentistry were integrated in a comprehensive, interdisciplinary health education system."1 This was consistent with the 1995 Institute of Medicine (IOM) report Dental Education at the Crossroads: Challenges and Change, ${ }^{2}$ which recommended that "to prepare future practitioners for more medically based modes of oral health care and more medically compromised patients, dental educators should work with their colleagues in medical schools and academic health centers." 
The purposes of our study were to:

1. review the literature on interprofessional education (IPE), and

2. assess the current status of interprofessional education and determine the extent of dental school participation in IPE by means of forty-one interviews conducted with administrators, deans, and associate deans at seven academic health centers (AHCs) in the United States in 2004.

\section{Review of the Literature}

Many terms in the area of interprofessional education are used interchangeably with seemingly precise, but differently interpreted meanings. ${ }^{3}$ The Center for the Advancement of Interprofessional Education (CAIPE) defines interprofessional education as "occasions when two or more professions learn from and about each other to improve collaboration and quality of care" (CAIPE 1997 revised). The World Health Organization (WHO) defines interprofessional education as "the process by which a group of students or workers from the healthrelated occupations with different backgrounds learn together during certain periods of their education, with interaction as the important goal, to collaborate in providing promotive, preventive, curative, rehabilitative, and other health-related services." 4

Fewer than 15 percent of U.S. medical and nursing schools have interdisciplinary programs. ${ }^{5,6}$ Many factors are perceived to be responsible for the lack of educational collaboration among the health care disciplines. Health professions education generally takes place in separate professional schools and distinct clinical areas. These schools and health care centers are managed by independent deans, directors, and department chairs. Professional schools have their own faculty, school calendars, and different points of entry into the profession. Separate schedules prevent the development of new courses and innovative curricula. ${ }^{7}$ Although some AHCs have revised their mission statements and written learning objectives related to interdisciplinary teams, few have stipulated that students must participate in an interdisciplinary program before graduation. ${ }^{8}$

For interdisciplinary programs to succeed, they must have the support of the administration of the educational and clinical institutions involved..$^{9,10}$ This support includes concurrent scheduling among schools to allow the time necessary for team process and development, as well as infrastructure modifications to allow physical proximity of team members in classroom, laboratory, clinical, or community learning environments. ${ }^{10,11}$ A recent report from the Association of Academic Health Centers $(\mathrm{AAHC})^{11}$ recommended that the federal government should create new funding to research, test, and evaluate various models of interprofessional education and practice. The report examined workforce shortages and quality of care and concluded that interprofessional practice is a critical element in health system reform that has not been sufficiently addressed and that doing so would require enhanced technology infrastructure and development of positive attitudes about the value of IPE among health professions educators from all disciplines. The AAHC report also concluded that interprofessional education will require development of a more integrated reimbursement system. This would require a change in current perceptions as well as infrastructure to allow proper billing for services rendered.

\section{Curriculum Development in Interprofessional Education}

In 2001 the Institute of Medicine (IOM) published the report Crossing the Quality Chasm: A New Health System for the $21^{\text {st }}$ Century. ${ }^{12}$ This report concluded that a major overhaul of the health care system was required and stressed that such a redesigned system should be predicated on multidisciplinary teams. It is unrealistic to expect health care providers to work in teams when they are not educated together and do not have the opportunity to learn teambased skills. The report concluded that:

All health care professionals should be edu-
cated to deliver patient-centered care as
members of an interdisciplinary team, em-
phasizing evidence-based practice, quality
improvement approaches, and information.

This IOM report explored core competencies across or within the health professions based on the efforts of the American Board of Internal Medicine Foundation (ABIMF) ${ }^{13}$ the American Association of Medical Colleges, ${ }^{14}$ the Center for the Advancement of Pharmaceutical Education Advisory Panel on Educational Outcomes, ${ }^{15}$ the Pew Health Professions Commission, ${ }^{16}$ and others. ${ }^{17,18}$ The Pew Health Professions Commission, for example, articulated seventeen competencies for future clinicians in $1992^{19}$ and later expanded the list to twenty-one. ${ }^{16}$ 
A follow-up IOM report-Health Professions Education: A Bridge to Quality ${ }^{20}$ —identified a set of five core competencies that all clinicians should possess, regardless of their discipline, to meet the needs of the twenty-first century health system. The proposed core competencies were:

- Provide patient-centered care: identify, respect, and care about patients' differences, values, preferences, and expressed needs; relieve pain and suffering; coordinate continuous care; listen to, clearly inform, communicate with, and educate patients; share decision making and management; and continuously advocate disease prevention, wellness, and promotion of healthy lifestyles, including a focus on population health.

- Work in interdisciplinary teams: cooperate, collaborate, communicate, and integrate care in teams to ensure that care is continuous and reliable.

- Employ evidence-based practice: integrate best research with clinical expertise and patient values for optimum care and participate in research activities to the extent feasible.

- Apply quality improvement: identify errors and hazards in care; understand and implement basic safety design principles, such as standardization and simplification; continually understand and measure quality of care in terms of structure, process, and outcomes in relation to patient and community needs; and design and test interventions to change processes and systems of care with the objective of improving quality.

- Utilize informatics: communicate, manage knowledge, mitigate error, and support decision making using information technology.

These are not the only interprofessional competency statements that have been developed. The American Council on Pharmaceutical Education (ACPE) adopted a series of accreditation standards focused on eighteen professional competencies, three of which related to interdisciplinary practice..$^{21}$ The Accreditation Council for Graduate Medical Education (ACGME) has formulated six competencies, one of which relates to interpersonal and communication skills that "result in effective information exchange and teaming with patients, their families, and other health professionals." 22 The National League for Nursing Accreditation Commission (NLNAC) competencies for 2005 included effective interdisciplinary team practice and asked that each nursing program interpret this and other competencies and related skills in the content, function, and structure of their program..$^{23}$

\section{Outcome Studies and Curricular Development Literature}

With few interprofessional programs to study, there is little research on their effectiveness. A Cochrane review attempted to assess the usefulness of interprofessional interventions compared to educational settings in which students from the various professions learned separately from each other. ${ }^{24} \mathrm{Of}$ the literature examined, none fulfilled the stringent inclusion criteria for this systematic review. Many of the studies reviewed lacked controls and failed to set adequate outcome criteria. ${ }^{25-29}$ Most were little more than reports of student satisfaction. The small number of studies that did include control groups suggested that, under favorable circumstances, interactive learning methods did not conclusively improve students' perceptions of other health care disciplines. ${ }^{30,31}$ Many studies had small or unreported sample sizes. Barr et al. ${ }^{32}$ and Hammick, ${ }^{33}$ in cooperation with the Joint Evaluation Team for Interprofessional Education (JET), developed a practical outcomes model based on that proposed by Kirkpatrick. ${ }^{34}$ This model classifies the outcomes of interprofessional education across four major levels, ranging from learners' reactions (lowest level) to benefits to patients (highest level). Their results indicated that interprofessional education that changes practice or benefited patients was most likely to occur in situations where the learners were already practicing clinicians.

A majority of the literature on interprofessional education programs is descriptive in nature, with the programs being located either at universities ${ }^{35-39}$ or as community-based courses. . $^{40-42}$

\section{Dental Education and Interprofessional Education}

The Health Professions Education: A Bridge to Quality IOM repor $\mathrm{t}^{20}$ placed special emphasis on nurses, pharmacists, physician assistants, and the allied health professionals, but according to the IOM committee, the allied health professions include "dental services." It should be noted that the dental profession was not represented on the committee or even among those attending the summit of interdisciplinary health care leaders that led to the report.

Evaluations of interprofessional education frequently report differences between the participant professions in attitudes toward each other and the program. Two British national surveys ${ }^{43,44}$ determined 
that nurses comprise the single largest group of participants in interprofessional programs for practitioners. Physicians and medical students were well represented relative to their overall numbers, while dentists and pharmacists were the least likely to be involved though they professed interest in participation. Organizational and logistic constraints were cited as the major obstacles to involvement. ${ }^{45}$

There is minimal participation of dental students in interprofessional education. Examples of interprofessional education that involve dental students are highly variable. Since 1996 the delivery of interprofessional learning modules at Dalhousie University has included health profession education programs in the Faculty of Health Professions. ${ }^{46}$ This faculty includes schools of Health and Human Performance, Health Services Administration, Human Communication Disorders, Nursing, Occupational Therapy, Physical Therapy, Pharmacy, Social Work, and the Clinical Vision Science and Disability Management Programs. In 1999, participation was extended to the Faculties of Medicine and Dentistry. One of the most successful modules is the "From Family Violence to Health" module. ${ }^{47}$ This module was grounded in the fact that dental professionals have a critical role in the identification and management of family violence, especially child abuse..$^{48}$ Initially almost all nondental students at Dalhousie University were unaware of the important role of the dental professional in the identification of potential abuse, and the interprofessional model increased students' understanding of the reporting of family violence.

Even though interprofessional education is in its infancy, models of provision must evolve in response to evaluation findings and reflection. A pilot project in Liverpool, England allowed final-year dental students to observe the roles of different members of the primary care team within a general medical practice setting. This evolved into general medical placements for all final-year dental students. Dental students reported that the visits to the medical practices increased their awareness of other professions and their confidence in communication with these individuals. ${ }^{49}$ Other IPE programs have been reported internationally; most of these reports were descriptions of pilot programs..$^{50-56}$ The authors of these papers reached a similar conclusion that students' early professional socialization plays a powerful role in dispelling some of their stereotypical perceptions of other health care providers. ${ }^{55}$ While many program directors felt that interdisci- plinary educational experiences would benefit their students, very few reported that they had incorporated these IPE pilot programs into their regular curricula, citing lack of resources and time as reasons..$^{50-56}$

\section{Methods}

The methodology for this study consisted of two phases: 1) a review of the literature on IPE in health professions education, the results of which were described in the previous section, and 2) a series of interviews with administrators and academic leaders at seven health science centers.

The previously described literature review was undertaken using PubMed, personal contacts with experts in the field, and hand searches of relevant literature. The literature search covered the years 1966 to 2004 and was conducted in 2004.

The interviewers were members of the American Dental Education Association (ADEA) Leadership Institute, a unique professional development program specifically for faculty in health professions education. This year-long program is designed to prepare the nation's most promising individuals at academic dental institutions to become future leaders in dental and higher education. Participants include faculty and administrators from dental, allied dental, and advanced dental education. Each class of the ADEA Leadership Institute is divided into several groups. Each group within the class is required to develop a Leadership Institute Project. The goals of the ADEA Leadership Institute group project are to 1) explore a particular issue so that the fellows acquire a thorough understanding of that issue from a broad perspective; 2) gain a perspective of the academic dental institution in the broad context of that issue, the parent institution, and the external environment; and 3) learn to work in a team. Small groups focus on a single issue and produce a paper suitable for publication based on the group's research. This project was developed to qualitatively evaluate the current status of interprofessional education at the institutions where the members of one Leadership Institute group were employed. ${ }^{62}$

A standardized set of questions was developed based on the findings of the literature review. The objective was to ascertain how AHC administrators, deans, and associate deans perceived IPE and determine the extent of interprofessional education at 
seven U.S. AHCs. Each of the interviewees was asked the same six questions:

1. What is your understanding of interprofessional education?

2. What are the principal barriers to interprofessional education?

3. What areas best lend themselves to interprofessional education?

4. Are any formal interprofessional activities incorporated in your predoctoral curricula?

5. Is there an individual or group on campus charged with development and coordination of interprofessional education?

6. How do you see the role of the dental school in interprofessional education?

Each of the authors interviewed four to seven administrators and educational leaders from their respective AHCs who were in a position to play a role in interprofessional education or be aware of IPE at their campus. These leaders, subsequently described in the results section, included senior members of the AHC administration and deans and academic affairs deans from the individual health profession schools. The subjects were informed of the purpose of the study and received the questions prior to the interview. The interviews were conducted face to face in the fall of 2004 in the subjects' offices. The interviews were not audiotaped. Interviewers recorded summaries and impressions of responses by writing notes during the conversation with the subjects.

Before any interviews were conducted, the authors evaluated the initial set of questions and edited them to make sure that all interviewers had a shared perception of the intent of each question. The authors/interviewers met once after each had completed several interviews to provide feedback on the process and to evaluate the suitability of the questions. After this meeting, the authors/interviewers returned to subjects who had already been interviewed to clarify their responses and thus ensure consistency among the authors. The remaining interviews were completed after this clarification round.

Each of the interviewers summarized the information collected in the interviews and submitted the material to two of the authors who collated the data and developed an overall summary of the responses to each question, including identification of commonly expressed opinions. The composite summary was then shared with all interviewers to ensure that it provided an accurate representation of the responses of the subjects. Summaries of the interviews were not returned to the subjects.

\section{Results}

The seven AHCs in this study were a convenience sample in that each of the authors was employed in one of these academic health centers. Each AHC had a dental, medical, and nursing school. Six of the AHCs had a public health school, five had pharmacy schools, and four had schools of allied health sciences with various disciplines represented. One of the AHCs had a school of osteopathic medicine. Six of the AHCs were state-supported institutions, and one $\mathrm{AHC}$ was a component of a private institution.

A total of forty-one interviews were conducted with respondents who represented the central administration of various schools at these seven AHCs. Seven top-level AHC administrators were interviewed including one university president, three provosts, two vice presidents for academic affairs, and an executive director for research and financial affairs. The dean of the dental school at each AHC was interviewed $(n=7)$. The remaining subjects were the deans of medicine (five), pharmacy (three), nursing (three), and public health (one) and the academic affairs deans from schools of dentistry (six), medicine (four), public health (two), social work (one), pharmacy (one), and nursing (one).

The subjects' responses to the six questions are summarized here.

1. What is your understanding of interprofessional education (IPE)?

The term "interprofessional education" was defined in various ways by the respondents. Interpretations ranged from simply combining biomedical courses for students from different health profession schools to more collaborative interaction between students. When biomedical courses are combined, cross-fertilization occurs. Students from different disciplines are taught together with a goal of developing a holistic view of patients' needs. Interviewees stated that the medical and dental students develop respect for each other's work and value the input of other health care professionals in the interdisciplinary team.

A wider definition suggests that interprofessional education is "an educational process during which individuals from multiple disciplines deliver the educational mission of the university." Appropriate disciplines to be involved in such a process include medicine, dentistry, nursing, social work, hospital administration, law, and business. 
Interprofessional education occurs also in multidisciplinary clinics, where members of different professions, and possibly residents and graduate students, work together to provide enhanced patient care. The most common multidisciplinary clinics that involve dentistry include cleft lip and palate clinics and geriatric care clinics.

2. What are the principal barriers to interprofessional education?

There was unanimous agreement that a major barrier to IPE was the lack of time in the curricula of the health profession schools. Interprofessional programs would have to replace current curricular content rather than be added on to the existing curriculum. The interviewees agreed with the IOM report Dental Education at the Crossroads that states that the "overcrowded dental curriculum gives students too little time to consolidate concepts and develop critical thinking skills that prepare them for lifelong learning." Scheduling common courses is complicated by different health profession schools operating under different academic term systems (the semester system versus a block scheme). The lack of physical proximity of the different schools also posed a problem; it was suggested that this might be overcome by working IPE into outreach programs, where students from different disciplines may work in the same clinical facilities.

The respondents described a perceived lack of administrative and faculty support for IPE. Many respondents stated that IPE is not viewed as a high priority and as such is not likely to be integrated into already crowded curricula. Some respondents described IPE as a "fad," as opposed to the traditional curriculum that has withstood the test of time. A common response was that IPE should be developed at the school level by a group of interested faculty and not initiated in the AHC provost's office. Respondents indicated that there is a level of faculty comfort in their "silos" and they have neither the time nor the inclination to become involved in IPE. A number of dental school deans and academic affairs deans bemoaned the failure of communication that exists within dental schools between the dental disciplines and specialties and the lack of curricular integration among these dental groups. The deans believed that this lack of coordination did not bode well for IPE, which involves disciplines beyond dentistry. Respondents reported that there are no incentives, either financial or in terms of promotion or career development, to become involved in IPE programs. Other interviewees stated that students desire a very focused education ("just give me what I need to know" attitude) and consequently IPE might be difficult to "market" to these students.

Many of the subjects indicated that current financial limitations make it difficult to obtain budgetary support for IPE. However, some respondents stated that budget cuts may actually force the university to look at integrating more courses to contain costs and, as such, financial constraints may be a facilitator of IPE rather than a barrier. Interviewees stated that the question of how tuition dollars would be distributed among the different schools involved in IPE programs had been raised on their campuses as a budgetary concern.

Concern was also expressed about the lack of scientific evidence for the effectiveness of IPE. Respondents indicated that the absence of high-quality outcome studies in the literature makes it hard to justify the expenditure of large amounts of time and money needed for IPE and stated that faculty will be skeptical until the effectiveness of this educational model has been established.

\section{What topics best lend themselves to inter- professional education?}

There was widespread agreement among the interviewees about the subject areas that best fit the interprofessional education model.

Ethics and professionalism are issues that are currently receiving much attention in the media, with many scandals in the business world and concerns about current ethical standards. Respondents stated that IPE courses on ethics and professionalism could best be carried out using small-group, case-based work. Interviewees stated that discussions would be greatly enriched by the participation of students from other health profession schools and by students from law and business schools. Several respondents commented that establishment of a center for ethics in the public domain involving members from the health profession schools, the law and business schools, and central administration might provide a central location on campus for development of interprofessional ethics programs.

Evidence-based practice is currently being embraced by all health professions. Interview subjects felt that many of the skills required to carry out evidence-based health care can be taught across the disciplines. These include the use of technology for searching the literature, biostatistics, data analysis, study design, and basic research methodology. Current students will be working in a very different environment from that which existed even ten years 
ago. The explosion in available information with widespread Internet access means that the future health care professional must be able to support decision making using information technology.

Interviewees described communication skills as another area where IPE could play a role and described many issues related to communication among health care professionals that are summarized below. All health care professionals must learn to communicate effectively with patients, staff, and other professionals. Many of the legal problems encountered by health care practitioners arise from a lack of effective communication with the patient. The ability of health care workers to communicate, collaborate, and integrate care in teams would ensure more continuous and reliable care for patients. While crossfunctional teams (CFTs) play an increasingly important role in health care, they often fail to function effectively. Interviewees described the perceived status difference (or pecking order) among health care professionals that reflects the professional hierarchy of medicine and may inhibit the interpersonal processes necessary for CFTS to function effectively. Interactions among future members of CFTs during their educational programs might help to mitigate these problems. Behavioral science programs and teamwork and leadership workshops could form an important component of an interprofessional program. Interviewees reported that a number of their schools have standardized patient programs and indicated that these programs should be run on an interprofessional basis so that students could learn to communicate effectively with colleagues as well as with patients.

Almost unanimously, interviewees suggested that the biomedical sciences could be taught across the professions. Other areas less frequently suggested for IPE included clinical care and patient-centered care. One interviewee suggested that clinical skills relating to overall patient health, including primary care, chronic disease management, care of the elderly, and promoting health and wellness, might appropriately be taught in an interprofessional setting. 4. Are any formal interprofessional activities incorporated into your predoctoral curriculum?

Of the seven AHCs investigated, five had basically no formal interprofessional education in the predoctoral curriculum, or IPE was limited to shared lectures in the biomedical sciences, with no planned interaction between students from different health profession schools. However, interviewees from most of the AHCs observed that ethics, communication and interpersonal skills, and biomedical science courses are taught in all of the component schools at the same AHC. Respondents from several AHCs reported that the individual health professions schools at their campus are currently modifying their strategic plans to align their goals with those of the overall university.

Two of the seven AHCs reported IPE activities summarized below. At one AHC, students from nursing, medicine, dentistry, pharmacy, social work, and the allied health professions participate in workshops on interprofessional teamwork and clinical rotations at outreach sites selected for their involvement in interprofessional health care. These community/campus partnerships give students the opportunity to work with students from different professions and provide health care to diverse communities in underserved areas. There has been little formal evaluation of these programs, and the interviewees agreed that such assessments were necessary.

Respondents from a second AHC reported ongoing interprofessional health care programs designed with the goal of improving the health status of the state's population by providing a multidisciplinary approach to health care. The hypothesis is that students who have been trained to work in interprofessional teams will be more likely to continue to work in underserved communities. Dental students between their junior and senior years complete an extramural clinical rotation based at the Area Health Education Center (AHEC). Medical, dental, and nursing students have the opportunity to learn to work in an interprofessional clinic and provide care for an underserved population. Another voluntary program involves an annual mission to a Latin American country, where medical and dental students provide team-based health care to a needy population. A byproduct of this program is a monthly free clinic, operated by teams of medical and dental students. While students favorably evaluated these programs, there has been little attempt to formally identify appropriate outcome measures and assess the effectiveness of these programs.

5. Is there an individual or group on campus who is charged with developing and coordinating interprofessional education?

Many participants in these interviews expressed the belief that it was important to have an Office of Education at the academic health center that coordinates interprofessional activities and works to develop new and innovative programs. Several interviewees reported that their universities had 
developed such offices that included the following components:

- Health Careers Center (HCC). The HCC provides information regarding health care careers to the interested college student.

- Interprofessional Education and Resource Center (IERC). This center provides state-of-the-art facilities that use technology and clinical simulation to prepare students to work as teams in provision of health care.

- Learning Commons. This program developed by the Office of Education and the biomedical library at one AHC offers faculty an opportunity to learn to use the latest technology in the teaching of evidence-based health care.

- Center for Health Interdisciplinary Programs (CHIP). This is a student-driven initiative developed with the goal of building interprofessional relationships and enhancing student education in the interprofessional arena. Dental, medical, nursing, pharmacy, veterinary, public health, and allied health students participate in this program.

- Health Sciences Committee Group (HSCG). The purpose of this unit at one of the AHCs is to investigate and develop courses that might be applied across the health sciences schools including research methodology, ethics, humanities/behavioral sciences, evidence-based practice, and health care delivery issues.

Many interview subjects expressed the opinion that the prospect for curricular collaboration among the health sciences colleges is contingent on internal and external funding. The universities have to provide seed funds to demonstrate their commitment to the program and to allow pilot projects to be developed.

6. How do you see the role of the dental school in interprofessional education?

Among the dental school deans and academic affairs deans there was widespread agreement that the dental school should play a pivotal role in interprofessional education. The IOM report Dental Education at the Crossroads stated that participation in cross-disciplinary education was imperative "to prepare future practitioners for more medically based modes of oral health care and more medically compromised patients. To achieve this goal, dental educators must work with their colleagues in medical schools and academic health centers." Interview subjects from dental schools expressed the opinion that it is essential to educate dental students with the skills, attitudes, knowledge, and values required to prac- tice within interdisciplinary health care teams. It was felt that this is critical in light of the ongoing investigation of the link between oral and systemic health and how oral diseases and disorders can compromise general health and well-being.

At the university level and among those individuals from the other health profession schools, responses were more variable. While many of the interviewees agreed that the dental school had an important role to play in interprofessional education, there was a sense that the dental school was somewhat isolated and less interested than other health professional schools in participating in IPE programs.

\section{Discussion}

It is proposed in the literature that more effective outcomes in dental education could be achieved if dentistry were integrated into a comprehensive interdisciplinary health care education system. This article has explored the state of interprofessional education at seven Academic Health Centers in the United States by interviewing forty-one leaders in these institutions.

Evaluation of the literature on IPE is complicated by the different interpretations of the term. This problem of variable interpretation was evident on reviewing the interviews. We believe that to be defined as interprofessional, educational experiences must involve students from various professions learning together as a team. Their collaborative interaction is characterized by the integration and modification of different professions' contributions in light of input from other professions. Simply putting different professional students together in the same lecture theater or having faculty from one school deliver lectures to students from other professional schools does not constitute effective interprofessional education.

With this definition in mind, our findings are that there is very little formal interprofessional education involving dental students in the predoctoral curricula of the investigated institutions. The findings suggest that IPE might be more appropriate and effective as electives in the predoctoral programs and at the postgraduate, residency, or continuing education level. Primary care and family practice clinics, psychiatric clinics, oral cancer centers, and cleft palate clinics were all cited as situations in which dental students could work and learn in teams with students from other health professions. The question of 
the ideal timing in the curriculum for IPE remains to be answered. Recommendations proposed in the literature range from the belief that, before embarking on interdisciplinary teamwork, the student must first have a thorough knowledge of his or her discipline $e^{10,25}$ to the suggestion that the experience of shared learning should occur early in the curriculum. ${ }^{57-59}$ It has been demonstrated that dysfunction in health care teams is often caused by the preconceptions brought to the situation by the various team members. ${ }^{60}$ Many health professionals are unaware of the precise role, abilities, and expertise of other professionals. Early team-training and shared educational experiences may help to break down these barriers and produce more effective interprofessional teams.

There was widespread agreement among the interview participants that ethics, communication skills, evidence-based practice, and use of informatics could and should be taught in an interprofessional arena. There was little mention of team building and leadership training by the respondents. However, we believe that these nonclinical skills will be essential in health care professionals who will work in interdisciplinary teams. Such skills are best taught in small group, case-based, or problem-based learning settings. ${ }^{61}$

The most commonly cited barrier to interprofessional education was the already overloaded curricula at the individual health profession schools. A number of interviewees suggested that IPE programs would have to take the place of previous courses and could not simply be added on to the already overfull curricula. We believe, however, that much of the material laid down in the core competencies is already being taught in the individual schools. The function of IPE programs would be to teach these concepts to groups of students from different schools, allowing them to interact and gain insight into the point of view of other professionals. Therefore, this problem and that of scheduling difficulties could most likely be overcome with sufficient flexibility and effort. The more difficult barriers to overcome are faculty and administration attitudes, many of whom believe that IPE is a "fad" or fashion while the traditional curriculum has withstood the test of time. Faculty attitudes are notoriously difficult to change. Such efforts are hindered in this context by the lack of high-quality outcome studies and adequate funding for IPE. The lack of rewards and incentives for faculty involvement were also felt to constitute an impediment to such programs. A recent report from the Association of Academic Health
Centers ${ }^{11}$ recommended that the federal government should create new funding to research, test, and evaluate various models of interprofessional education and practice.

The interviewees from the dental schools at the various institutions were overwhelmingly in favor of becoming involved in interprofessional activities. Unfortunately, this was not the perception among administrators at other health professions schools. There did not appear to be opposition to the participation of dental schools, but there was a general impression that dental schools were isolated from the other schools at AHCs. It appears that there may be a lack of communication among the health professions schools at AHCs and this highlights the need for designating an individual on campus with overall responsibility for promoting, developing, and coordinating interprofessional activities on campus.

\section{Future Directions}

The findings reported here represent a preliminary study based on a convenience sample of fortyone respondents at seven AHCs that were the home institutions of the authors of this article. Therefore, it would be helpful to expand the research to survey all North American dental schools and educational leaders at their parent institutions to develop a more extensive inventory of ideas for implementing changes within academic health centers and the role of dental schools within these centers.

\section{Conclusions}

The conclusions from this study may be outlined as follows:

- Dental education faces a number of challenges in its efforts to produce practitioners who will function effectively in the rapidly changing environment in which they will work.

- Future dentists will play an integral role in interdisciplinary health care teams.

- It seems logical that health professions students, including dental students, who will work together in interdisciplinary teams should be educated together in interprofessional programs

- Currently, there are minimal formal interprofessional activities in the predoctoral curricula at the seven institutions investigated in this preliminary study. 
- To prove the usefulness of interprofessional education programs, high-quality outcome studies must be conducted.

- For successful IPE on campus, there must be commitment from both administration and faculty. There must be a designated person with overall responsibility for promoting, developing, and coordinating interprofessional activities on campus, and there must be financial support for such programs.

- The dental school can play a pivotal role in interprofessional education by communicating, more effectively, its interest in participation in campus-wide interprofessional initiatives.

We believe that interprofessional interactions can be fostered and teamwork can be enhanced by IPE, resulting in better delivery of health care that is safer, more effective, and cost-effective. There must be adequate communication to ensure that these needs are met.

\section{REFERENCES}

1. At: www.santafegroup.org. Accessed: February 6, 2005.

2. Field MJ, ed. Dental education at the crossroads: challenges and change. An Institute of Medicine Report. Washington, DC: National Academies Press, 2001.

3. Barr H. Interprofessional education: today, yesterday, and tomorrow-a review. London: UK Center for the Advancement of Interprofessional Education, 2001. At: www.CAIPE.org.uk. Accessed: August 26, 2004.

4. Learning together to work together for health. Report of a WHO study group on multiprofessional education of health personnel: the team approach. World Health Organization Technical Report Series. Geneva: World Health Organization, 1988;769:1-72.

5. Baldwin DC, Jr. Some historical notes on interdisciplinary and interprofessional education and practice in health care in the United States. J Interprof Care 1996;10:173-87.

6. Larson EL. New rules for the game: interdisciplinary education for health professionals. Nurs Outlook 1995; 43:180-5.

7. Holmes DE, Osterweis M. Catalysts in interdisciplinary education. Washington, DC: Association of Academic Health Centers, 1999.

8. Stephenson KS, Peloquin SM, Richmond SA, Hinman $\mathrm{MR}$, Christiansen $\mathrm{CH}$. Changing educational paradigms to prepare allied health professions for the $21^{\text {st }}$ century. Educ Health 2002;15:37-49.

9. Makaram S. Interprofessional cooperation. Med Educ 1995;29:65S-9S.

10. Mariano C. The case for interdisciplinary collaboration. Nurs Outlook 1999;37:285-8.

11. Kelch R, Osterweis M. Health professions and quality care: the promises and limitations of interprofessional practice. Washington, DC: Association of Academic Health Centers, 2004.
12. Institute of Medicine. Crossing the quality chasm: a new health system for the $21^{\text {st }}$ century. Washington, DC: National Academies Press, 2001.

13. ABIM Foundation. Medical professionalism in the new millennium: a physician charter. Ann Intern Med 2002; 136:243-6.

14. American Association of Medical Colleges. Medical school objectives project, 2001. At: www.aamc.org/ meded/msop/start.htm. Accessed: July 23, 2004.

15. Center for the Advancement of Pharmaceutical Education [CAPE] Advisory Panel on Educational Outcomes. Educational outcomes, 2004. At: www.aacp.org. Accessed: July 23, 2004.

16. O'Neil EH and the Pew Health Professions Commission. Recreating health professional practice for a new century: the fourth report of the PEW Health Professions Commission. San Francisco: Pew Health Professions Commission, 1998.

17. Brady M, Leuner JD, Bellack JP, Loquist RS, Cipriano $\mathrm{PF}, \mathrm{O}$ 'Neil EH. A proposed framework for differentiating the 21 PEW competencies by level of nursing education. Nurs Health Care Perspect 2001;22:30-5.

18. Halpern R, Lee MY, Boulter PR, Phillips RR. A synthesis of nine major reports on physicians' competencies for the emerging practice environment. Acad Med 2001;76: 606-15.

19. O'Neil EH. Education as part of the health care solution: strategies from the Pew Health Professions Commission. JAMA 1992;268:1146-8.

20. Institute of Medicine. Health professions education: a bridge to quality. Washington, DC: National Academies Press, 2003.

21. American Council on Pharmaceutical Education. Accreditation standards and guidelines for the professional program in pharmacy leading to the Doctor of Pharmacy degree. 1997. At: www.acpe-accredit.org. Accessed: August 27, 2004.

22. ACGME 2002. At: www.acgme.org. Accessed: August 27, 2004.

23. National League for Nursing Accrediting Commission. At: www.nlnac.org. Accessed: August 27, 2004.

24. Zwarenstein M, Reeves S, Barr H, Hammick M, Koppel I, Atkins J. Interprofessional education: effects on professional practice and health care outcomes (Cochrane Review). In: The Cochrane Library, Issue 2. Chichester, UK: John Wiley \& Sons, Ltd., 2004.

25. Carpenter J. Interprofessional education for medical and nursing students: evaluation of a program. Med Educ 1995;29:265-72.

26. Cobia DC, Center H, Buckhalt JA, Meadows ME. An interprofessional model for serving youth at risk for substance abuse: the team case study. J Drug Educ 1995; 25:99-109.

27. Connolly PM. Transdisciplinary collaboration of academia and practice in the area of serious mental illness. Aust $\mathrm{N}$ Z J Ment Health Nurs 1995;4:168-80.

28. Harmon RL, Sheehy LM, Davis DM. The utility of external performance measurement tools in program evaluation. Rehabil Nurs 1998;23:8-11.

29. Lia-Hoagberg B, Nelson P, Chase RA. An interdisciplinary health team training program for school staff in Minnesota. J Sch Health 1997;67:94-7. 
30. Dienst ER, Byl N. Evaluation of an educational program in health care teams. J Community Health 1981;6:282-98.

31. Falconer JA, Roth EJ, Sutin JA, Strasser DC, Chang RW. The critical path method in stroke rehabilitation: lessons from an experiment in cost containment and quality improvement. Qual Rev Bull 1995;19:8-16.

32. Barr H, Hammick M, Koppel I, Reeves S. Evaluating interprofessional education: two systematic reviews for health and social care. Br Educ Res J 1999;25:533-44.

33. Hammick M. Interprofessional education: evidence for the past to guide the future. Med Teach 2000;22:461-7.

34. Kirkpatrick DL. Evaluation. In: Craig R, Bittel L, eds. Training and development handbook. New York: McGraw-Hill, 1967.

35. Mitchell PH. Health sciences partnerships in interprofessional education (HSPICE): implementing and sustaining interprofessional education in a researchintensive university. Washington, DC: Association of Academic Health Centers, 2002.

36. Ohia SE. Establishing the Creighton University Office of Interprofessional Education. Washington, DC: Association of Academic Health Centers, 2002.

37. Taillie JS. Academic health centers take a leading role to advance interdisciplinary education and practice in prevention. Washington, DC: Association of Academic Health Centers, 2003.

38. Cerra FB, Brandt BF. Building a sustainable environment for interprofessional education within the University of Minnesota's Academic Health Center. Washington, DC: Association of Academic Health Centers, 2004.

39. Buck MM, Tilson ER, Andersen JC. Implementation and evaluation of an interdisciplinary health professions core curriculum. J Allied Health 1999;28(3):174-8.

40. Harris DL, Henry RC, Bland CJ, Starnaman SM, Voytek $\mathrm{KL}$. Lessons learned from implementing multidisciplinary health professions educational models in community settings. J Interprofessional Care 2003;17:7-20.

41. Henry RC. Community partnership model for health professions education. J Am Podiatr Med Assoc 1993;83: 328-31.

42. Lilley SH, Clay M, Greer A, Harris J, Cummings HD. Interdisciplinary rural health training for health professional students: strategies for curriculum design. J Allied Health 1998;27:208-12.

43. Shakespeare H, Tucker W, Northover J. Report of a national survey on interprofessional education in primary health care. London: Center for Advancement of Interprofessional Education, 1989.

44. Barr H, Waterton S. Interprofessional education in health and social care in the United Kingdom: report of a CAIPE survey. London: Center for Advancement of Interprofessional Education, 1996.

45. Owens C, Goble R, Pereira Gray D. Involvement in multiprofessional continuing education: a local survey of 24 health care professions. J Interprofessional Care 1999; 13:277-88.

46. Johnston GM, Banks S. Interprofessional learning modules at Dalhousie University. J Health Admin Educ 2000; $18: 407-27$
47. Johnson G, Ryding HA, Campbell LM. Evolution of interprofessional learning: Dalhousie University's "From family violence to health" module. J Can Dent Assoc 2003; 69:658.

48. Murphy JM, Welbury RR. The dental practitioner's role in protecting children from abuse. Part I. The child protection system. Br Dent J 1998;184:7-10.

49. Ireland RS, Dawber S. Introducing undergraduate dental students to the wider role of the primary care team. Eur J Dent Educ 1999;3:145-7.

50. Mouradian WE, Berg JH, Somerman MJ. Addressing disparities through dental-medical collaborations. Part I. The role of cultural competency in health disparities: training of primary care medical practitioners in children's oral health. J Dent Educ 2003;67:860-8.

51. Mouradian WE, Corbin SB. Addressing disparities through dental-medical collaborations. Part II. Cross-cutting themes in the care of special populations. J Dent Educ 2003;67:1320-6.

52. Mouradian WE, Huebner C, DePaola D. Addressing disparities through dental-medical collaborations. Part III. Leadership for the public good. J Dent Educ 2004;68:505-12.

53. Ogden GR, Green M, Ker JS. The use of interprofessional peer examiners in an objectively structured clinical examination: can dental students act as examiners? Br Dent J 2000;189:160-4.

54. Wessel GL, Colangelo GA. Integrating an interdisciplinary collaborative health education project for dental and nursing students. Natl Acad Pract Forum-Issues in Interdisciplinary Care 1999;1:165-9.

55. Reeves S, Pryce A. Emerging themes: an exploratory research project of an interprofessional education module for medical, dental, and nursing students. Nurs Educ Today 1998;18:534-41.

56. Holt L, Bray K, Mayberry B, Overman P. Assessing interdisciplinary education in US dental hygiene programs. J Allied Health 2000;29:235-40.

57. Anvaripour PL, Jacobson L, Schweiger J, Weissman GK. Physician-nurse collegiality in the medical curriuculum: exploratory workshop and student questionnaire. Mt Sinai J Med 1991;58:91-4.

58. Headrick LA, Richardson A, Priebe GP, Bergman D. Continuous improvement learning for residents. Pediatrics 1998;101:768-73.

59. Wahlstrom O, Sanden I, Hammar M. Multiprofessional education in the medical curriculum. Med Educ 1997; $31: 425-9$

60. Lichtenstein R, Alexander JA, McCarthy JF, Wells R. Status differences in cross-functional teams: effects on individual member participation, job satisfaction, and intent to quit. J Health Soc Behav 2004;45:322-35.

61. Bruhn JG. Problem-based learning: an approach toward reforming allied health education. J Allied Health 1992;21:161-73.

62. ADEA Leadership Institute. At: www.adea.org/leadership/ LIMain.html. Accessed: November 25, 2005. 